\title{
Impact of abiraterone acetate with and without prior docetaxel chemotherapy on the survival of patients with metastatic castration-resistant prostate cancer: a population-based study
}

Joice Rocha PhD, Armen G. Aprikian MD, Marie Vanhuyse MD, Fabio L. Cury MD, Jason Hu BSc, Noémie Prévost MSc, Alice Dragomir PhD

\section{Abstract}

Background: Abiraterone acetate was introduced in Quebec in 2012 for the treatment of metastatic castration-resistant prostate cancer (mCRPC) in patients who had received chemotherapy with docetaxel. This study describes abiraterone use in the early postapproval period and its clinical effectiveness in Quebec, for both patients who had received docetaxel chemotherapy and those who could not receive docetaxel therapy owing to medical reasons.

Methods: A retrospective cohort study was conducted using Quebec public health care administrative databases. Our cohort consisted of patients with MCRPC who received abiraterone between January 2012 and June 2013. Treatment groups were defined as patients who received abiraterone following docetaxel chemotherapy and those who received abiraterone without having had chemotherapy, under the "exception patient" measure. Study outcomes included overall survival, duration of abiraterone therapy and number of hospital days. Cox proportional hazard regression was used to estimate the effectiveness of abiraterone adjusted for several covariates.

Results: Our cohort consisted of 303 patients with mCRPC treated with abiraterone (99 after chemotherapy and 204 as exception patients). The median age at initiation of abiraterone therapy was 75.0 for the postchemotherapy group and 80.0 for the exception patient group. The corresponding median survival values were 12 and 14 months (log-rank test $p=0.8$ ). Risk of death was similar in the 2 groups (adjusted hazard ratio 0.89 [95\% confidence interval 0.57-1.38]).

Interpretation: The effectiveness of abiraterone in older patients who were ineligible for chemotherapy was similar to that of patients with prior docetaxel exposure. Overall, the real-world survival benefits of abiraterone were similar to those in the COU-AA-301 trial.

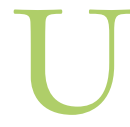
ntil recently, chemotherapy with docetaxel was the only therapeutic option offering survival benefits for patients with metastatic castration-resistant prostate cancer (mCRPC). ${ }^{1}$ Further research into targeting androgen signalling led to the discovery of a new steroidogenesis inhibitor, abiraterone acetate. Abiraterone is a direct inhibitor of the cytochrome $\mathrm{P} 450 \mathrm{c} 17$ and has a global effect on the synthesis of steroids including extragonadal, testicular and intratumoral androgens. ${ }^{2}$ The COU-AA-301 study was the first phase III clinical trial evaluating abiraterone at $1000 \mathrm{mg}$ with $5 \mathrm{mg}$ of prednisone twice a day in patients with mCRPC pretreated with docetaxel. ${ }^{3}$ The median overall survival was improved by about 4.6 months in the abiraterone plus prednisone group compared to the placebo plus prednisone group (15.8 mo v. $11.2 \mathrm{mo}$; hazard ratio $0.74,95 \%$ confidence interval $[\mathrm{CI}] 0.64-0.86 ; p<$ $0.001){ }^{3}$ Patients who received abiraterone treatment showed improvement in their quality of life and a moderate toxicity profile. ${ }^{4}$ The COU-AA-302 trial was a second trial evaluating abiraterone in chemotherapy-naive patients with

Competing interests: Dr. Aprikian reports personal fees from Janssen and grants and personal fees from Astellas Pharma outside the submitted work. No other competing interests were declared.

This article has been peer reviewed.

Correspondence to: Alice Dragomir, alice.dragomir@muhc.mcgill.ca CMAJ Open 2017. DOI:10.9778/cmajo.20160082 
minimally symptomatic mCRPC. ${ }^{5}$ Again, patients who received abiraterone showed improvement in survival and secondary outcomes.

Abiraterone became available for patients with mCRPC in Quebec in 2012 via the publicly funded provincial drug plan, with special conditions. Access to abiraterone is restricted to 2 categories of patients: those who have received chemotherapy with docetaxel and those who cannot receive docetaxel owing to medical reasons, for whom the prescribing physician is required to request authorization using the "exception patient" measure. In 2014, other drugs such as enzalutamide and radium-223 became available in Quebec for men with mCRPC who had received docetaxel, ${ }^{6,7}$ and abiraterone became available for minimally asymptomatic patients who had not received docetaxel. ${ }^{5}$

The objective of the current study was to characterize the pattern of use of abiraterone in Quebec since it became available in the province and to evaluate survival in patients who received abiraterone after docetaxel chemotherapy or as exception patients, using a retrospective observational cohort from the Quebec public health care administrative database.

\section{Methods}

\section{Study design}

We conducted an observational retrospective cohort study using data from the Régie de l'assurance maladie du Québec (RAMQ) and Med-Echo databases, both of which administer the public health insurance program in Quebec. The RAMQ has 4 types of databases: 1) the beneficiary database (age, sex, social assistance status and date of death for all those registered), 2) the medical services data set, which contains medical claims for all inpatient and ambulatory services (date, nature and location of the medical services, diagnoses [International Classification of Diseases, 9th revision (ICD-9)], procedure codes and associated costs), 3) the admissibility database, which lists the periods of eligibility for the RAMQ's public health insurance plan, and 4) the pharmaceutical database, which provides data on medications dispensed in community drugstores including date, drug name, dosage, quantity, dose form, duration of therapy and drug costs (insured and/or paid by patients). All databases contain a unique identifier, the patient's health insurance number, which serves as a link between them. The Med-Echo database contains information on acute care hospital stays (date of admission, length of stay, primary diagnosis and up to 15 secondary diagnoses).

\section{Study population}

The study population consisted of men 40 years or older with a diagnosis of prostate cancer who received androgen deprivation therapy (orchiectomy or luteinizing hormone-releasing hormone analogues or antagonists) between January 2001 and June 2013 and who received their first abiraterone treatment between January 2012 and June 2013. Treatment groups were defined as patients who received abiraterone following docetaxel chemotherapy and those who received abiraterone without having had chemotherapy, as exception patients.
We defined the index date as the start date of abiraterone therapy (first abiraterone prescription). The study period was defined as the index date until death, loss of RAMQ coverage or Dec. 31, 2013.

\section{Covariates}

We identified age, residence (rural/urban administrative provincial region) and proximity to a radiation oncology centre at the index date based on data from the beneficiary database. We identified the presence of comorbidities in the 1-year period before the index date using common name drug codes $^{6}$ from the pharmaceutical database, and diagnosis codes and medical service procedure codes from the medical services data set and Med-Echo database. Comorbidities identified included cardiovascular events and chronic diseases such as diabetes, hypertension and dyslipidemia, which are known to be associated with increased risk of cardiovascular disease and associated mortality. ${ }^{8-13}$

Cardiovascular events were defined as follows: coronary heart disease: ICD-9 codes 410-414, ICD-10 codes 122125 , a medical procedure (coronary artery bypass grafting, angiography or angioplasty) or use of oral nitrate therapy; cerebrovascular disease: ICD-9 codes 430-438 or medical procedures; chronic heart failure: ICD-9 code 398.91, 402 or 428 , or a prescription of furosemide with digoxin, angiotensin-converting-enzyme inhibitors, spironolactone or $\beta$-blockers; and diagnosis of arrhythmia: ICD-9 codes $426-427$, a medical procedure using a pacemaker and the use of drugs for cardiac arrhythmias (amiodarone, digoxin, quinidine, disopyramide, flecainamide, mexiletine, procainamide, propafenone or sotalol). ${ }^{14}$ Diagnosis or treatment of chronic diseases was defined as follows: diabetes: ICD-9 code 250, or use of insulin or hypoglycemic agents; dyslipidemia: ICD-9 code 272 or use of lipid-lowering drugs; hypertension: ICD-9 codes 401-404 or use of thiazides, angiotensinconverting-enzyme inhibitors without furosemide, calciumchannel blockers or $\beta$-blockers without other markers of coronary artery disease.

In addition, we estimated overall health status using a modified Von Korff Chronic Disease Score ${ }^{15}$ at the index date. Having received medication used to prevent skeletalrelated events due to bone metastases, also called bonetargeted therapy (denosumab or zoledronic acid), and having received palliative radiotherapy before or during the study period were considered covariates.

\section{Statistical analysis}

Patient characteristics are presented as percentages, means (with $95 \% \mathrm{CI}$ ) and medians (with interquartile range [IQR] or $95 \% \mathrm{CI}$ ), as applicable. We used $t$ tests and $\chi^{2}$ tests to assess differences between groups in patient characteristics (treatments and comorbidities), abiraterone treatment duration and number of days in hospital (all causes and those related to prostate cancer). We performed quantile regression to assess the impact of prior docetaxel exposure on the median days of prostate-cancerrelated hospital stay, adjusted for several covariates. ${ }^{16,17}$ 
Survival since initiation of abiraterone therapy was evaluated with the use of Kaplan-Meier analysis ${ }^{18}$ and differences between abiraterone groups with the use of the logrank test. We used the Cox proportional hazards model to estimate the hazard ratio of prior docetaxel exposure, adjusted for several covariates, which respected the proportional hazards assumption. In addition, we used the direct adjusted survival function to estimate the survival curves as well as the adjusted median and mean survival of the average patient in the 2 treatment groups. ${ }^{19}$ This method estimates the direct adjusted survival function by averaging the predicted survival functions for each combination of covariates. We performed the analyses using SAS version 9. All tests were 2 -sided with a significance threshold of $5 \%$.

\section{Ethics approval}

Ethics approval for this study was obtained from the McGill University Health Centre Ethics Board and the Commission d'accès à l'information du Québec before data were obtained from the RAMQ.

\section{Results}

\section{Study population}

Our cohort consisted of 303 patients with mCRPC treated with abiraterone between January 2012 and June 2013, of whom 99 (32.7\%) received abiraterone following chemotherapy with docetaxel and 204 (67.3\%) received abiraterone without having had chemotherapy, as exception patients (Figure 1). The median age was 75.0 (IQR 68.0-81.0) years for the postchemotherapy group and 80.0 (IQR 76.0-84.0) years for the exception patient group (Table 1); most of the patients in the exception patient group were 75 years or older (155 [76.0\%] v. 48 [48.5\%] in the postchemotherapy group, $p<0.001)$. A total of 169 $(82.8 \%)$ of the exception patients had a diagnosis of metastasis, compared to $95(96.0 \%)$ of those in the postchemotherapy group ( $p=0.001$ ). A higher proportion of patients in the chemotherapy group than in the exception patient group received bone-targeted therapy $(86[86.9 \%]$ v. $140[68.6 \%], p<0.001)$ and palliative radiation $(25[25.2 \%]$ v. $20[9.8 \%], p<0.001)$.

Table 1 shows the proportion of comorbidities overall and for the 2 treatment groups. The most prevalent comorbid

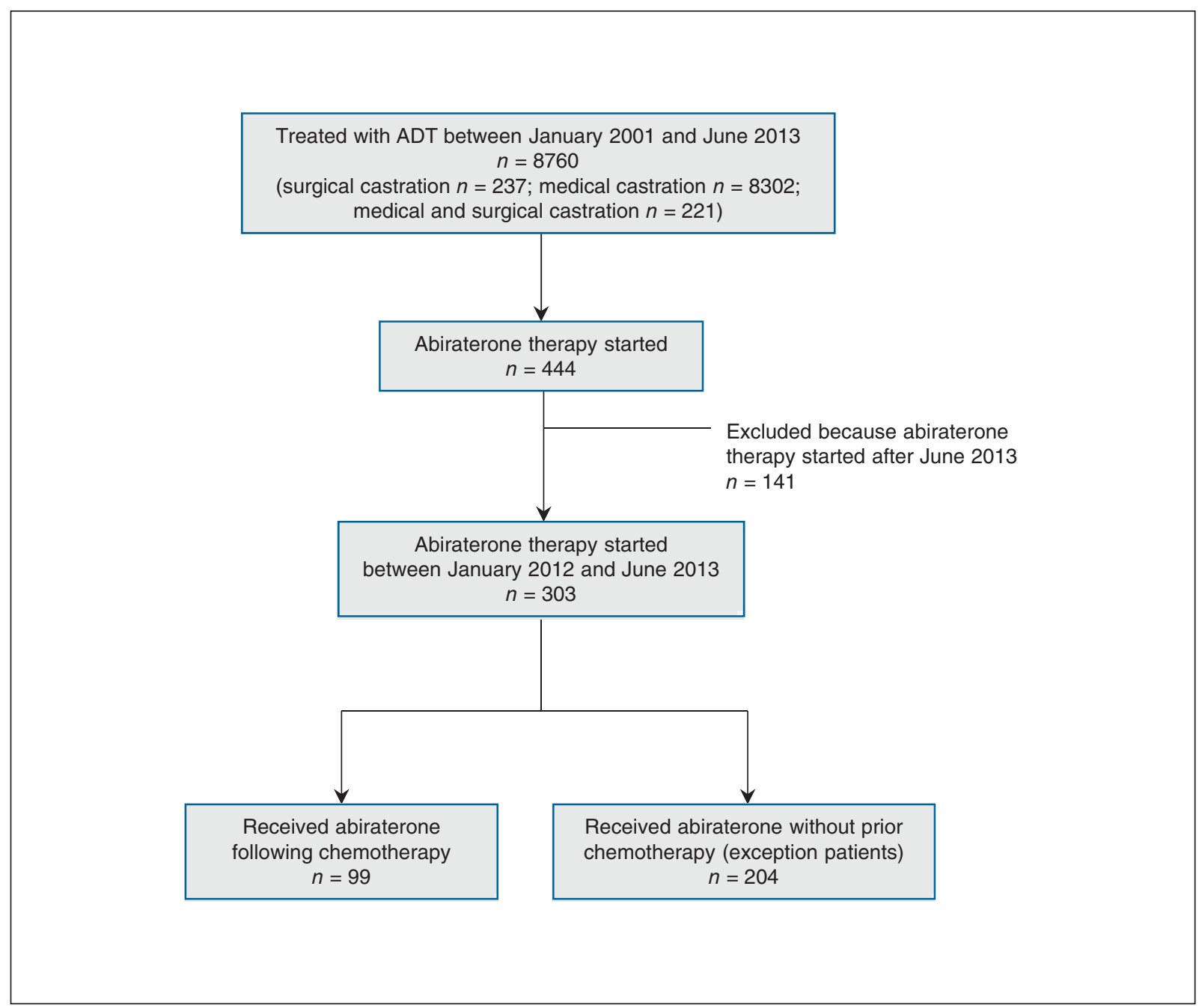

Figure 1: Flow chart of cohort selection. Note: $A D T$ = androgen deprivation therapy (medical or surgical). 


\section{OPEN}

Research

condition identified was hypertension (> 70\% in both groups). All other comorbidities were consistently lower in the chemotherapy group than in the exception patient group; however, only the difference for cardiac arrhythmia was statistically significant $(p=0.01)$.

\section{Duration of abiraterone therapy and hospital days}

A median duration of chemotherapy of 4 cycles was observed in the postchemotherapy group (Table 2). The median duration of abiraterone therapy was 6.0 months overall, 5.3 months for the postchemotherapy group and 5.9 months for the exception patient group. Patients in the postchemotherapy group experienced an additional 3 days in hospital compared to the exception patients (mean $13.7 \mathrm{v}$. $10.9 \mathrm{~d}, p=0.001$ ); most hospital days for the former group were related to prostate cancer. Quantile regression analyses showed an association between prior chemotherapy exposure and increased prostate-cancer-related hospital days (3.0 d [95\% CI 0.37-8.63]) when adjusted for the covariables (Table 3 ).

\begin{tabular}{|c|c|c|c|c|}
\hline \multirow[b]{2}{*}{$\begin{array}{l}\text { Demographic and treatment } \\
\text { characteristics }\end{array}$} & \multicolumn{3}{|c|}{ Treatment group; no. (\%) of patients* } & \multirow[b]{2}{*}{$p$ value } \\
\hline & $\begin{array}{l}\text { Overall } \\
n=303\end{array}$ & $\begin{array}{l}\text { Following docetaxel } \\
\text { chemotherapy } \\
n=99\end{array}$ & $\begin{array}{c}\text { Without prior } \\
\text { docetaxel } \\
\text { chemotherapy } \\
\text { (exception patients) } \\
n=204\end{array}$ & \\
\hline \multicolumn{5}{|l|}{$\begin{array}{l}\text { Age at initiation of } \\
\text { abiraterone therapy, yr }\end{array}$} \\
\hline Mean $(95 \% \mathrm{Cl})$ & $78.0(77.1-78.9)$ & $74.5(72.7-76.2)$ & $79.7(78.8-80.7)$ & $<0.001$ \\
\hline Median (IQR) & $79.0(73.0-84.0)$ & $75.0(68.0-81.0)$ & $80.0(76.0-84.0)$ & $<0.001$ \\
\hline $\begin{array}{l}\text { Age at initiation of } \\
\text { abiraterone therapy } \geq 70 \mathrm{yr}\end{array}$ & $254(83.8)$ & $69(69.7)$ & $185(90.7)$ & $<0.001$ \\
\hline $\begin{array}{l}\text { Age at initiation of } \\
\text { abiraterone therapy } \geq 75 \mathrm{yr}\end{array}$ & $203(67.0)$ & $48(48.5)$ & $155(76.0)$ & $<0.001$ \\
\hline Diagnosed metastasis & $264(87.1)$ & $95(96.0)$ & $169(82.8)$ & 0.001 \\
\hline Prior chemotherapy & $99(32.7)$ & $99(100)$ & $0(0)$ & - \\
\hline $\begin{array}{l}\text { Received anti-androgens } \\
\text { during CRPC }\end{array}$ & $43(14.2)$ & $17(17.2)$ & $26(12.7)$ & 0.3 \\
\hline $\begin{array}{l}\text { Received LHRHa during } \\
\text { CRPC }\end{array}$ & $238(78.5)$ & $88(88.9)$ & $150(73.5)$ & 0.002 \\
\hline Bone-targeted therapy & $226(74.6)$ & $86(86.9)$ & $140(68.6)$ & $<0.001$ \\
\hline Palliative radiotherapy & $45(14.9)$ & $25(25.2)$ & $20(9.8)$ & $<0.001$ \\
\hline $\begin{array}{l}\text { Proximity to radiation } \\
\text { oncology centre }\end{array}$ & $219(72.3)$ & $69(69.7)$ & $150(73.5)$ & 0.5 \\
\hline Rural residence & $61(20.1)$ & $16(16.2)$ & $45(22.0)$ & 0.2 \\
\hline \multicolumn{5}{|l|}{ Comorbidity } \\
\hline Diabetes & $64(21.1)$ & $15(15.2)$ & $49(24.0)$ & 0.1 \\
\hline Dyslipidemia & $165(54.4)$ & $53(53.5)$ & $112(54.9)$ & 0.8 \\
\hline Hypertension & $225(74.2)$ & $72(72.7)$ & $153(75.0)$ & 0.7 \\
\hline Coronary heart disease & $78(25.7)$ & $25(25.2)$ & $53(26.0)$ & 0.9 \\
\hline Chronic heart failure & 27 (8.9) & $5(5.1)$ & $22(10.8)$ & 0.1 \\
\hline Cerebrovascular disease & $10(3.3)$ & $1(1.0)$ & $9(4.4)$ & $0.2+$ \\
\hline Arrhythmia & $48(15.8)$ & $8(8.1)$ & $40(19.6)$ & 0.01 \\
\hline \multicolumn{5}{|c|}{ Von Korff Chronic Disease Score } \\
\hline Mean $(95 \% \mathrm{Cl})$ & $12.0(11.5-12.5)$ & $11.8(11.0-12.6)$ & $12.0(11.4-12.7)$ & 0.8 \\
\hline Median (IQR) & $12.0(9.0-15.0)$ & $12.0(9.0-15.0)$ & $12.0(9.0-15.0)$ & 0.9 \\
\hline
\end{tabular}




\begin{tabular}{|c|c|c|c|c|c|}
\hline \multirow[b]{2}{*}{ Variable } & & \multirow[b]{2}{*}{ Overall } & \multicolumn{2}{|l|}{ Treatment group } & \multirow[b]{2}{*}{$p$ value } \\
\hline & & & $\begin{array}{c}\text { Following } \\
\text { docetaxel } \\
\text { chemotherapy }\end{array}$ & $\begin{array}{l}\text { Without prior } \\
\text { docetaxel } \\
\text { chemotherapy }\end{array}$ & \\
\hline \multicolumn{6}{|c|}{$\begin{array}{l}\text { Duration of therapy with primary } \\
\text { medication }\end{array}$} \\
\hline \multirow[t]{2}{*}{ Abiraterone, mo } & Mean $(95 \% \mathrm{Cl})$ & $6.4(5.9-6.9)$ & $6.0(5.2-6.7)$ & $6.6(5.9-7.3)$ & 0.7 \\
\hline & Median (IQR) & $6.0(3.0-8.3)$ & $5.3(3.0-7.5)$ & $5.9(3.0-9.0)$ & 0.7 \\
\hline \multirow[t]{2}{*}{ Abiraterone, $d$} & Mean $(95 \% \mathrm{Cl})$ & 191 (176-207) & 178 (157-200) & $197(177-217)$ & 0.7 \\
\hline & Median (IQR) & $176(90-249)$ & $158(90-224)$ & $178(90-270)$ & 0.7 \\
\hline \multirow{2}{*}{$\begin{array}{l}\text { Chemotherapy, no. of } \\
\text { cycles }\end{array}$} & Mean $(95 \% \mathrm{Cl})$ & $1.6(1.3-1.9)$ & $4.9(4.3-5.5)$ & - & - \\
\hline & Median (IQR) & $0(1.0-2.0)$ & $4.0(3.0-7.0)$ & - & - \\
\hline \multicolumn{6}{|l|}{ Hospital days } \\
\hline \multirow{2}{*}{$\begin{array}{l}\text { Prostate-cancer- } \\
\text { related }\end{array}$} & Mean $(95 \% \mathrm{Cl})$ & $11.4(8.6-14.2)$ & $13.2(9.2-17.1)$ & $10.5(6.8-14.2)$ & 0.006 \\
\hline & Median (IQR) & $3(0-15)$ & $7(0-18)$ & $1(0-13.5)$ & 0.01 \\
\hline \multirow[t]{2}{*}{ All causes } & Mean $(95 \% \mathrm{Cl})$ & $11.8(9.0-14.6)$ & $13.7(9.7-17.7)$ & $10.9(7.2-14.6)$ & 0.001 \\
\hline & Median (IQR) & $4(0-15)$ & $7(0-20)$ & $2(0-14)$ & 0.012 \\
\hline
\end{tabular}

\section{Survival}

Overall, 123 patients died during the study period, 41 (41.4\%) in the postchemotherapy group and $82(40.2 \%)$ in the exception patient group. Figure 2 presents the Kaplan-Meier survival curves by treatment group. The 18-month overall survival rate was $40.3 \%$ and $41.3 \%$ in the postchemotherapy and exception patient groups, respectively. The corresponding median survival values were 12 months (IQR 6-19; 95\% CI 11-19) and 14 months (IQR 6-not available [third quartile not yet reached]; $95 \%$ CI 11-20), respectively (log-rank test $p$ value 0.8 ). The Cox proportional hazards model adjusted for covariates is presented in Table 4. The proportional hazards assumption was respected for all variables except for palliative radiation, which was used as a time-dependent variable. A similar risk of death was estimated in the 2 treatment groups (hazard ratio 0.89 [95\% CI $0.57-$ 1.38]). Having received palliative radiation (hazard ratio 2.80 [95\% CI 1.75-4.50]) and having chronic heart failure (hazard ratio 1.88 [95\% CI 1.03-3.40]) were found to be independent predictors of death. The direct adjusted survival curves are presented in Figure 2. The adjusted mean survival values were 13.3 months (95\% CI 11.6-15.3) and 12.2 months (95\% CI 11.013.8 ) in the postchemotherapy and exception patient groups, respectively. The corresponding adjusted median survival was 14 months (IQR 6-not available) in both groups.

\section{Interpretation}

Perhaps surprisingly, the early adoption of abiraterone in Quebec (2012) accounted for only 33\% of all patients using this drug during the study period following docetaxel chemo- therapy; most received abiraterone without prior docetaxel therapy because they could not receive docetaxel owing to medical reasons (considered exception patients). The availability of abiraterone under the exception patient measure for patients who appeared borderline with regard to chemotherapy eligibility may have been favoured in the early years of abiraterone access in Quebec. Our results suggest that patients ineligible for chemotherapy who received abiraterone under the exception patient measure received some survival benefit as opposed to receiving only best supportive care. Survival for this group was similar to that for the postchemotherapy group. Exception patients were on average older and had more comorbid conditions than patients in the postchemotherapy group. Moreover, a lower proportion received supportive treatments such as bone-targeted therapy and palliative radiotherapy, a higher proportion lived in rural areas, and they had fewer hospital days. Yet, similar effectiveness of abiraterone was found in the 2 groups after adjustment for several covariates. This means that, despite the frail condition of patients who are not eligible for chemotherapy, they may still tolerate and respond adequately to abiraterone. The duration of abiraterone treatment in our study, which was slightly shorter in the postchemotherapy group than in the exception patient group, supports this notion.

The median survival in our postchemotherapy group (12.0 [95\% CI 11.0-19.0] mo) was slightly less than that observed in the COU-AA-301 trial $^{3}$ (15.8 [95\% CI 14.8-17.0] mo), whereas the latter is similar to the survival in our exception patient group (14.0 [95\% CI 11-20] mo). However, our patients were older than those in the COU-AA-301 trial 


\section{OPEN}

Research

(median age 75.0 [IQR 68.0-81.0] yr in the postchemotherapy group and 80.0 [IQR 76.0-84.0] yr in the exception patient group, compared to 69.0 [IQR 42.0-95.0] yr in the trial), and the trial patients may have had a different comorbidity or disease profile, which we were unable to assess. In a

\begin{tabular}{|lc|}
\hline $\begin{array}{l}\text { Table 3: Quantile regression of median prostate-cancer- } \\
\text { related hospital days }\end{array}$ & $\begin{array}{c}\text { Adjusted estimate } \\
\text { (95\% Cl) }\end{array}$ \\
\hline Variable & $3.00(0.37$ to 8.63$)$ \\
\hline $\begin{array}{l}\text { Treatment group } \\
\text { (postchemotherapy v. exception } \\
\text { patient) }\end{array}$ & $-1.00(-4.93$ to 3.47$)$ \\
\hline $\begin{array}{l}\text { Age at initiation of abiraterone } \\
\text { therapy ( } \geq 70 \text { v. < } 70 \text { yr) }\end{array}$ & $1.00(-1.44$ to 3.22$)$ \\
\hline Bone-targeted therapy (yes v. no) & $3.00(-0.69$ to 7.85$)$ \\
\hline Palliative radiotherapy (yes v. no) & $2.00(-2.29$ to 3.41$)$ \\
\hline $\begin{array}{l}\text { Proximity to radiation oncology } \\
\text { centre (yes v. no) }\end{array}$ & $0.00(-3.28$ to 2.60$)$ \\
\hline Rural residence (yes v. no) & $0.00(-3.88$ to 4.46$)$ \\
\hline Diabetes (yes v. no) & $2.00(0.08$ to 6.74$)$ \\
\hline Dyslipidemia (yes v. no) & $2.00(-0.52$ to 3.99) \\
\hline Hypertension (yes v. no) & $-1.00(-3.49$ to 1.93$)$ \\
\hline Coronary heart disease (yes v. no) & $-2.00(-4.21$ to 5.44$)$ \\
\hline Chronic heart failure (yes v. no) & $2.00(-4.29$ to 20.23$)$ \\
\hline Cerebrovascular disease (yes v. no) & $1.00(-2.56$ to 4.69$)$ \\
\hline Arrhythmia (yes v. no) & \\
\hline Note: Cl = confidence interval. & \\
\hline
\end{tabular}

recent study, Clayton and colleagues ${ }^{20}$ evaluated the survival of 187 patients with a median age of 73 years who received abiraterone after docetaxel therapy in 3 Canadian provinces. Patients without prior chemotherapy, who most likely corresponded to our exception patient group, were excluded from their cohort because of their study period (between 2011 and 2012). Similar to our postchemotherapy cohort, the median survival from initiation of abiraterone therapy was $11(95 \%$ CI 8.0-13.0) months. A study conducted in Austria with 270 patients (mean age $73.5 \mathrm{yr}$ ) showed a median survival of 11 months but suggested a higher median survival among those aged $46-76$ years $(17 \mathrm{mo}){ }^{21}$ Poon and colleagues ${ }^{22}$ reported a median overall survival of 15.5 (95\% CI 13.8-23.6) months in 52 patients who received abiraterone after docetaxel therapy; again, their cohort was younger than ours (median age $66 \mathrm{yr}$ ). Other studies have shown results similar to those of the COU-AA-301 trial; , $^{23}$ however, the patients who received abiraterone without prior docetaxel therapy were either excluded or represented abiraterone use in both the symptomatic and asymptomatic setting.

\section{Limitations}

Our study presents limitations mainly owing to the use of administrative databases. First, we cannot completely rule out the use of abiraterone in asymptomatic patients and/or in patients with less advanced disease because our data did not include baseline clinical information. However, given the similar survival in the postchemotherapy and exception patient groups, it is likely that most patients presented with symptomatic disease. Furthermore, public funding for abiraterone in asymptomatic patients started in March 2014, whereas our study period ended in December 2013. No identification of a precise date of entry into the CRPC phase (except for patients

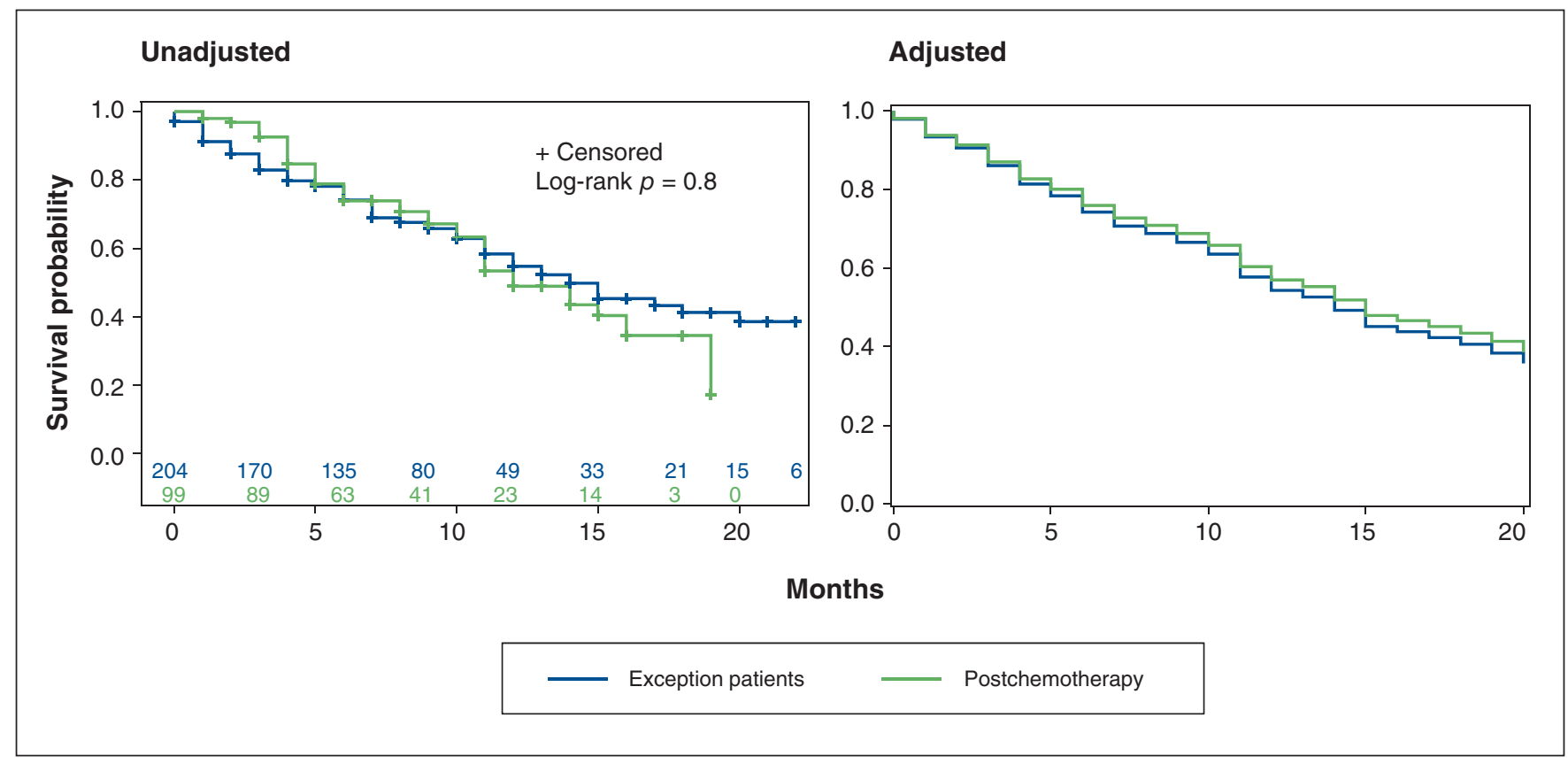

Figure 2: Left: Kaplan-Meier estimates of unadjusted overall survival for the postchemotherapy and exception patient groups. Right: direct adjusted survival curves adjusted for the covariates included in the Cox regression model. 
Table 4: Cox proportional hazards analysis of overall survival

\begin{tabular}{|lcc|}
\hline Variable & \multicolumn{1}{c}{$\begin{array}{c}\text { Univariate } \\
\text { hazard ratio } \\
(95 \% \mathrm{Cl})\end{array}$} & $\begin{array}{c}\text { Adjusted hazard } \\
\text { ratio } \\
(95 \% \mathrm{Cl})\end{array}$ \\
\hline $\begin{array}{l}\text { Treatment group } \\
\text { (postchemotherapy v. } \\
\text { exception patient) }\end{array}$ & $1.05(0.72-1.52)$ & $0.89(0.57-1.38)$ \\
\hline $\begin{array}{l}\text { Age at initiation of } \\
\text { abiraterone therapy } \\
\text { ( } \geq 70 \text { v. }<70 \text { yr) }\end{array}$ & $0.63(0.41-0.99)$ & $0.72(0.44-1.19)$ \\
\hline $\begin{array}{l}\text { Bone-targeted therapy } \\
\text { (yes v. no) }\end{array}$ & $0.94(0.62-1.41)$ & $0.90(0.58-1.39)$ \\
\hline $\begin{array}{l}\text { Palliative radiotherapy* } \\
\text { (yes v. no) }\end{array}$ & $2.80(1.91-4.11)$ & $2.80(1.75-4.50)$ \\
\hline $\begin{array}{l}\text { Proximity to radiation } \\
\text { oncology centre (yes v. } \\
\text { no) }\end{array}$ & $0.96(0.65-1.42)$ & $0.89(0.58-1.39)$ \\
\hline $\begin{array}{l}\text { Rural residence (yes v. } \\
\text { no) }\end{array}$ & $0.93(0.59-1.45)$ & $0.92(0.56-1.50)$ \\
\hline Diabetes (yes v. no) & $1.45(0.97-2.16)$ & $1.33(0.85-2.08)$ \\
\hline Dyslipidemia (yes v. no) & $0.90(0.63-1.29)$ & $0.89(0.60-1.33)$ \\
\hline Hypertension (yes v. no) & $0.95(0.63-1.42)$ & $0.79(0.49-1.26)$ \\
\hline $\begin{array}{l}\text { Coronary heart disease } \\
\text { (yes v. no) }\end{array}$ & $1.08(0.73-1.60)$ & $1.01(0.65-1.59)$ \\
\hline $\begin{array}{l}\text { Chronic heart failure } \\
\text { (yes v. no) }\end{array}$ & $2.15(1.30-3.56)$ & $1.88(1.03-3.40)$ \\
\hline $\begin{array}{l}\text { Cerebrovascular } \\
\text { disease (yes v. no) }\end{array}$ & $1.33(0.54-3.25)$ & $1.81(0.71-4.62)$ \\
\hline Arrhythmia (yes v. no) & $1.28(0.82-2.02)$ & $1.02(0.60-1.74)$ \\
\hline $\begin{array}{l}\text { Note: Cl = confidence interval. } \\
\text { *Time-dependent variable. }\end{array}$ & & \\
\hline & & \\
\hline
\end{tabular}

receiving chemotherapy or abiraterone, with the use of therapy index dates) was possible, so we could not identify a control group of clinically similar patients with mCRPC who did not receive chemotherapy or abiraterone to compare our group of exception patients. Also, we lacked patient clinical information such as prostate-specific antigen levels and testosterone levels, Eastern Cooperative Oncology Group performance status, extent of metastatic disease, symptoms and quality-of-life measures.

\section{Conclusion}

The use of abiraterone in older patients with multiple comorbidities and a short life expectancy may provide similar benefits to those observed in patients receiving abiraterone following docetaxel chemotherapy in clinical trials as well as in real-life settings. It would be worthwhile to compare the survival of patients receiving abiraterone under the exception patient measure to that of patients receiving no treatment. This was not possible in our study. Our findings can inform clinicians and decision-makers on the appropriateness of abiraterone therapy in patients deemed too frail for chemotherapy. Similar outcomes studies with other newly approved mCRPC drugs (e.g., enzalutamide and radium-223) are needed to evaluate their use outside of the setting of clinical trials and to assist the clinical decisionmaking process, so that treatment selection can be based not only on evidence from clinical trials but also on real-world clinical practice.

\section{References}

1. Tannock IF, de Wit R, Berry WR, et al.; TAX 327 Investigators. Docetaxel plus prednisone or mitoxantrone plus prednisone for advanced prostate cancer. N Engl 7 Med 2004;351:1502-12.

2. Salem M, Garcia JA. Abiraterone acetate, a novel adrenal inhibitor in metastatic castration-resistant prostate cancer. Curr Oncol Rep 2011;13:92-6.

3. Fizazi K, Scher HI, Molina A, et al.; COU-AA-301 Investigators. Abiraterone acetate for treatment of metastatic castration-resistant prostate cancer: final overall survival analysis of the COU-AA-301 randomised, double-blind, placebo-controlled phase 3 study. Lancet Oncol 2012;13:983-92.

4. de Bono JS, Logothetis CJ, Molina A, et al.; COU-AA-301 Investigators. Abiraterone and increased survival in metastatic prostate cancer. $N$ Engl $7 \mathrm{Med}$ 2011;364:1995-2005.

5. Ryan CJ, Smith MR, Fizazi K, et al.; COU-AA-302 Investigators. Abiraterone acetate plus prednisone versus placebo plus prednisone in chemotherapy-naive men with metastatic castration-resistant prostate cancer (COU-AA-302): final overall survival analysis of a randomised, double-blind, placebo-controlled phase 3 study. Lancet Oncol 2015;16:152-60.

6. List of medications. Québec: Régie de l'assurance maladie du Québec (RAMQ); 2016. Available: www.ramq.gouv.qc.ca/en/regie/legal-publications/ Pages/list-medications.aspx (accessed 2016 Mar. 24).

7. Liste des médicaments fournis en établissements. Québec: Régie de l'assurance maladie du Québec (RAMQ); 2016. www.ramq.gouv.qc.ca/fr/regie/ publications-legales/Pages/liste-medicaments-etablissements.aspx (accessed 2016 Mar. 24).

8. Berry JD, Dyer A, Carnethon $M$, et al. Association of traditional risk factors with cardiovascular death across 0 to 10,10 to 20 , and $>20$ years follow-up in men and women. Am 7 Cardiol 2008;101:89-94.

9. Nielsen JB, Graff C, Rasmussen PV, et al. Risk prediction of cardiovascular death based on the QTc interval: evaluating age and gender differences in a large primary care population. Eur Heart 7 2014;35:1335-44.

10. Monesi L, Tettamanti M, Cortesi L, et al. Elevated risk of death and major cardiovascular events in subjects with newly diagnosed diabetes: findings from an administrative database. Nutr Metab Cardiovasc Dis 2014;24:263-70.

11. Zambon A, Arfe A, Corrao G, et al. Relationships of different types of event to cardiovascular death in tials of antihypertensive treatment: an aid to definition of total cardiovascular disease risk in hypertension. 7 Hypertens 2014;32: 495-508.

12. Nguyen PL, Je Y, Schutz FA, et al. Association of androgen deprivation therapy with cardiovascular death in patients with prostate cancer: a metaanalysis of randomized trials. FAMA 2011;306:2359-66.

13. Saigal CS, Gore JL, Krupski TL, et al. Androgen deprivation therapy increases cardiovascular morbidity in men with prostate cancer. Cancer 2007;110. 1493-500.

14. Dragomir A, Côté R, Roy L, et al. Impact of adherence to antihypertensive agents on clinical outcomes and hospitalization costs. Med Care 2010;48:418-25.

15. Von Korff M, Wagner EH, Saunders K. A chronic disease score from automated pharmacy data. 7 Clin Epidemiol 1992;45:197-203.

16. Yin G, Cai J. Quantile regression models with multivariate failure time data. Biometrics 2005;61:151-61.

17. Lorenz N. Using quantile and asymmetric least squares regression for optimal risk adjustment. Health Econ 2016 June 13 [Epub ahead of print]. doi:10.1002/hec.3352.

18. Klein J, Moeschberger ML. Survival analysis: techniques for censored and truncated data. 2nd ed. New York: Springer; 2003.

19. Zhang X, Loberiza FR, Klein JP, et al. A SAS macro for estimation of direct adjusted survival curves based on a stratified Cox regression model. Comput Methods Programs Biomed 2007;88:95-101.

20. Clayton R, Wu J, Heng DY, et al. A multicentre analysis of abiraterone acetate in Canadian patients with metastatic castration-resistant prostate cancer. Can Urol Assoc 7 2014;8:E583-90.

21. Mohamad Al-Ali B, Kramer G, Madersbacher S, et al. Abiraterone for castration-resistant prostate cancer: adherence, survival and hospitalization. Wien Klin Wochenschr 2016 Sept. 5 [Epub ahead of print]. doi:10.1007/ s00508-016-1067-9.

22. Poon DM, Chan $\mathrm{K}$, Lee $\mathrm{SH}$, et al. Abiraterone acetate in metastatic castration-resistant prostate cancer - the unanticipated real-world clinical experience. BMC Urol 2016;16:12

23. Van Praet C, Rottey S, Van Hende F, et al. Abiraterone acetate postdocetaxel for metastatic castration-resistant prostate cancer in the Belgian compassionate use program. Urol Oncol 2016;34:254 e7-13. 
24. Svensson J, Andersson E, Persson U, et al. Value of treatment in clinical trials versus the real world: the case of abiraterone acetate (Zytiga) for postchemotherapy metastatic castration-resistant prostate cancer patients in Sweden. Scand 7 Urol 2016;50:286-91.

Affiliations: Division of Urology (Rocha, Aprikian, Hu, Prévost, Dragomir), Department of Surgery, McGill University; Research Institute of the McGill University Health Centre (Rocha, Hu, Prévost, Dragomir); Division of Medical Oncology (Vanhuyse) and Division of Radiation Oncology (Cury), Department of Oncology, McGill University; McGill University Health Centre (Aprikian, Vanhuyse, Cury), Montréal, Que.

Contributors: Joice Rocha and Alice Dragomir conceived and designed the study with input from Armen Aprikian, Marie Vanhuyse and Fabio Cury. Alice Dragomir and Noémie Prévost performed the statistical and cost-effectiveness analyses. Joice Rocha, Alice Dragomir, and Jason $\mathrm{Hu}$ wrote the first draft of the article, with further contributions from Armen Aprikian, Marie Vanhuyse and Fabio Cury. All of the authors contributed substantially to the interpretation of the data, provided critical feedback, approved the final version to be published and agreed to act as guarantors of the work.

Funding: This work was funded by a Prostate Cancer Canada Discovery Grant (no. 2013). Alice Dragomir obtained salary support from the CotéSharp Family Foundation at the McGill University Health Centre. Since June 2016 she is a Fonds de Recherche du Québec - Santé Junior 1 Research Scholar.

Supplemental information: For reviewer comments and the original submission of this manuscript, please see www.cmajopen.ca/content/5/1/ E265/suppl/DC1 